\title{
Ecoalfabetização: ensinando a ler a natureza
}

\author{
Shaula Maíra Vicentini Sampaio ${ }^{1}$ \\ Universidade Federal do Rio Grande do Sul - UFRGS \\ Maria Lúcia Castagna Wortmann ${ }^{2}$ \\ UFRGS e Universidade Luterana do Brasil - ULBRA
}

resumo: Neste artigo, discutimos alguns significados atribuídos à natureza, praticados na ecoalfabetização, vertente da educação ambiental que consiste na busca por maneiras de operacionalizar a sustentabilidade ecológica, por meio da observação e do aprendizado com os sistemas naturais. Uma das representações culturais que discutimos refere um suposto afastamento ocorrido entre ser humano e natureza como a principal causa do desequilíbrio ecológico. Assim, nossos modos de vida seriam cada vez menos "naturais". Argumentamos, entre outros aspectos, que o que se entende por "natural" não possui um significado intrínseco, mas é construído na cultura. Queremos registrar ainda que essas construções definidoras do que é e do que não é "natural", possuem efeitos constitutivos, políticos e pedagógicos que atuam fortemente sobre a vida das pessoas. Desse modo, a alfabetização ecológica, ao incentivar que aprendamos com os "princípios ecológicos", promove determinadas leituras e interpretações preferenciais da natureza. Entre essas, a de que a natureza é perfeita, harmônica e sábia. Autores que criticam a ecoalfabetização identificam nela um acentuado determinismo ecológico, pois essa se valeria da transposição de regras da natureza para governar a sociedade.

palavras-chave: Ecoalfabetização, Representações de natureza, Estudos culturais.

abstract: This article discusses about some meanings attributed to nature and practiced by ecoliteracy, approach on Environmental Education which consists of the search for implementing ways to sustainable ecology, by the use of observation and apprenticeship of the environmental systems. One of the cultural representations discussed here is about a presumed separation between human being and nature, that would be the main reason for the ecological unbalance. If, by this thought, it can be supposed that our way of life is becoming less "natural", it is defended here that the word "natural" doesn't have an inherent meaning, but is a cultural

\footnotetext{
1 e-mail: shaula_maira@yahoo.com.br

2 e-mail:wortmann@terra.com.br
} 
construction. We register that these defining constructions concerning what is and what isn't "natural" obtain constitutive effects, political and pedagogic. Ecoliteracy critics argue that it can be identified as an ecological determinism, considering that some rules from natural world are transposed to rule society.

keywords: Ecoliteracy, Nature representations, Cultural studies.

\section{Introdução}

... um gramado é um objeto artificial, composto de objetos naturais, ou seja, grama. O gramado tem por finalidade representar a natureza, e essa representação acaba por substituir a natureza própria do lugar por uma natureza em si natural mas artificial em relação ao lugar. Em suma: custa; o gramado requer labutas sem termo: para semeá-lo, regá-lo, adubá-lo, desinfetá-lo, apará-lo (CALVINO, 1994, p. 29).

A epígrafe retirada de um texto de Ítalo Calvino brinca com as representações do que seja "natural" ou "artificial". Dependendo de onde esteja, do trabalho que despende, de como construímos e nos relacionamos com as coisas, essas podem ser classificadas como naturais ou artificiais e isso indica que os significados são culturalmente produzidos, não estando, portanto, grudados nos objetos a que se referem, o que é bem traduzido pela metáfora do gramado acima apresentada. Neste artigo, iremos ampliar um pouco mais o questionamento que introduzimos ao falar desse "gramado", discutindo alguns significados atribuídos à natureza praticados em uma "vertente" - se é que é possível considerá-la assim - da educação ambiental, a "ecoalfabetização" ou "alfabetização ecológica".

A alfabetização ecológica foi desenvolvida pelo físico Fritjof Capra no Centro de Ecoalfabetização (Center for Ecoliteracy) ${ }^{3}$, localizado

3 Mais informações em http://www.ecoliteracy.org. No site do Instituto Ecoar, podem ser encontrados alguns materiais produzidos no Center for Ecoliteracy traduzidos para o português (http:// www.ecoar.org.br). 
em Berkeley, Califórnia ${ }^{4}$. Sumariamente, pode-se dizer que Capra (2003a) propõe a ecoalfabetização como uma busca por maneiras de operacionalizar a sustentabilidade ecológica, sugerindo que, para isso, procuremos inspiração nos ecossistemas naturais, que são comunidades sustentáveis.

Para desenvolvermos a discussão que aqui propomos, nos reportaremos a questões que emergiram em uma dissertação de mestrado que lidou com a "produção" de identidades de educadores ambientais (SAMPAIO, 2005), a partir do acompanhamento de um curso de formação continuada de professores ${ }^{5}$ oferecido por um órgão público da cidade de Porto Alegre, RS, cujo título foi, exatamente, "Ecoalfabetização e Ecopedagogia". Cumpre destacar que, apesar de outras temáticas também terem sido trabalhadas nesse curso, nele foi dado um enfoque bastante acentuado às leituras da natureza promovidas pela ecoalfabetização.

Focalizaremos, aqui, especialmente, as representações culturais ${ }^{6}$ de natureza acionadas durante o curso, a partir da citação de excertos retirados do diário de campo elaborado durante o acompanhamento do

4 É importante mencionar, como lembra Layrargues (2003), que a abordagem da alfabetização ecológica mais divulgada e popularizada é de responsabilidade não apenas de Fritjof Capra, mas também de David Orr. Além disso, Layrargues (id.) também indica que muitos dos fundamentos da ecoalfabetização, aproximam-se da tendência, anteriormente formulada, denominada "Earth Literacy", desenvolvida, principalmente, por Steve Van Matre.

5 O curso teve carga horária de 40 horas e foi ministrado por um professor que atua no movimento ambientalista gaúcho há muitos anos. Dele participaram cerca de 20 professoras da rede municipal de ensino de Porto Alegre, as quais lecionam para diversas áreas do conhecimento e diferentes níveis de ensino (da educação infantil à educação de jovens e adultos).

${ }^{6}$ Utilizamos o conceito de representação cultural na direção que é proposta por alguns intelectuais relacionados ao campo dos Estudos Culturais, como, por exemplo, Stuart Hall (1997). Na linha de pesquisa Estudos Culturais em Educação, do Programa de Pós-graduação em Educação da Universidade Federal do Rio Grande do Sul, esse conceito tem sido bastante importante para se discutir temáticas relacionadas à educação e, até mesmo, à educação ambiental (ver: WORTMANN, 2001a; WORTMANN, 2001b; GUIMARÃES; SAMPAIO, 2004). 
curso $^{7}$. Além disso, recorremos a entrevistas feitas com as alunas do curso, a alguns textos nos quais Capra discorre sobre a ecoalfabetização, bem como a textos de autores que criticam esse desdobramento pedagógico das teorias sistêmicas disseminadas por este físico.

\section{"O ser humano afastou-se da natureza...": a construção discursiva do natural}

Algumas das questões que problematizamos referem-se não apenas à ecoalfabetização, mas aos discursos da educação ambiental de forma mais geral. Por exemplo, quando se propala um presumido afastamento entre o "homem" e a "natureza", como se explicita no excerto do diário de campo que apresentamos a seguir:

Luiza $^{8}$ perguntou como controlar o surgimento de pragas e Henrique [nome fictício do professor do curso] afirmou que não há como fazer isso. Ela argüiu: "Como não? Mas se existe um desequilíbrio?" O professor respondeu que o desequilíbrio é antrópico e não da natureza. (...) Ele falou sobre a codependência, o fato de que "todos precisam de todos para manter o sistema funcionando e essa noção foi o ser humano quem mais perdeu quando se afastou da natureza por medo, por tantas raz̃ẽs, e é a noção mais importante que nós temos que recuperar" (DIÁRIO DE CAMPO, 14/10/2003, destaques nossos).

Nessa passagem do diário de campo, o professor frisa, de modo enfático, que não há como solucionar os problemas ambientais, como, por exemplo, a ocorrência de pragas na agricultura, pois o desequilíbrio não está na natureza, mas no "homem". Suas argumentações culpam os seres humanos pelo afastamento da natureza e indicam os inúmeros malefícios decorrentes de tal afastamento. Ao enfatizar que a sobrevivência do planeta dependerá de necessárias mudanças de atitudes, ele de certa forma invoca um discurso totalizador, pois

\footnotetext{
${ }^{7} \mathrm{Nas}$ análises que realizamos, foram utilizados, também, trechos de textos que foram enviados por e-mail às alunas do curso pesquisado, os quais funcionaram, assim, como um material de apoio às aulas presenciais.

8 Estamos usando nomes fictícios para garantir o anonimato dos sujeitos que participaram da pesquisa.
} 
inviabiliza qualquer refutação. Além disso, há um caráter normalizador nessa asserção, pois se entende que há um comportamento correto que deve ser adotado pelas pessoas, a fim de corrigir essa situação de afastamento da natureza, tida como um comportamento errado e pernicioso que deve ser abandonado. Isto é, se visa proceder a uma classificação e, conseqüentemente, à normalização das ações humanas.

Nesse sentido, ao indicar que estamos insistentemente desrespeitando as "leis da natureza", ratificando o distanciamento apontado, estaria sendo igualmente afirmado que estaríamos acentuando a crise. Busca-se, então, definir o que é natural, colocandose em evidência o que não é, devendo essa última possibilidade ser revista e transformada. Assinalamos que esses arranjos discursivos engendram um caráter severamente disciplinador à educação ambiental, apontando o que precisa ser suprimido nas condutas dos indivíduos e em muitos sentidos determinando o que é considerado aceitável. Por outro lado, argumentamos que o que se entende por "natural" não possui um significado intrínseco, mas é construído na cultura, atuando nessa construção as próprias representações veiculadas no curso e nas muitas outras instâncias ocupadas com a educação ambiental. Ainda assim, queremos registrar que essas construções definidoras do que é e do que não é "natural" possuem efeitos constitutivos, políticos e pedagógicos que atuam fortemente sobre a vida das pessoas.

Além disso, como destaca Thomas Kesselring (2000), é importante reconhecer que as nossas atuais compreensões de "natureza" ou de "natural" não são nem foram as únicas. Na pesquisa desenvolvida por Marise Amaral (1997a), a partir de anúncios publicitários que produzem representações culturais de natureza, a autora mostrou, por exemplo, que a natureza e a cultura interagem por meio de processos de significação nos quais o "natural" pode assumir diversos significados, tais como: beleza, aventura, perigo, perfeição, entre outros. Possivelmente, os significados atribuídos ao "natural" nos artefatos culturais estudados por Amaral (id.) não são os mesmos que os postos em circulação pelos discursos da ecoalfabetização, já que os interesses acionados na produção das representações culturais neles instituídas são bastante diferenciados, pois, no primeiro caso, esses se 
direcionam especialmente a um interesse mercadológico. Como aponta Amaral (2000b), "a produção discursiva sobre a natureza se reveste de muitas roupagens, passando dos discursos biológico, ecológico, ativista, médico, filosófico, econômico a discursos produzidos pela articulação entre peças publicitárias, a divulgação na mídia das descobertas/ espetáculos da ciência, os documentários de História Natural e os filmes de ficção científica" (p. 235).

Nos "discursos ecoalfabetizadores", o "natural" funciona como parâmetro de uma vida desejável, porque mais aproximada de uma natureza idealizada, como está sugerido no excerto abaixo:

O professor indicou que as pessoas estão "esticando a vida e diminuindo a qualidade de vida" e deu o exemplo da cidade de Veranópolis, que, segundo ele, é um dos lugares onde há a maior longevidade do Estado. Ele disse que "Veranópolis é um lugar natural", onde as pessoas "pegam muito na enxada, tomam muito vinho e fazem muita festa (...); aquilo ali que é qualidade de vida” (DIÁRIO DE CAMPO, 23/10/2003, destaque nosso).

Assim, como contraponto à vida urbana configurada como globalizada e "desaculturada", exalta-se, nesta última fala, o "natural", como um modo de viver rural, compreendido como mais aproximado da terra e mais fiel às características do ambiente físico. Atribuindo o rótulo de "natural" ao tipo de vida que se leva, por exemplo, na cidade de Veranópolis" ${ }^{9}$ estabelecem-se, a partir de uma oposição, as formas de vida que são artificiais: as que são urbanas e alheias aos ciclos da natureza. Como está salientado no excerto, não é por acaso que essa vida caracterizada como "artificial" e de "pouca qualidade" corresponde à maneira como a maior parte das pessoas vive atualmente. Assim, esse modo de vida configurado como "não-natural" seria um grave sintoma da crise que vivenciamos, consideração que me remete novamente a considerar a problemática do "desequilíbrio", que se estaria processando nas sociedades contemporâneas.

9 Município localizado na Serra Gaúcha, no qual a média de vida é bastante elevada. 
A educação ambiental (e, nesse caso, mais especificamente a ecoalfabetização), vista a partir de tal focalização, imbui-se, então, de uma vontade de potência (GRÜN, 1996), intencionando prescrever os meios pelos quais lograríamos alcançar esse pretenso estado de equilíbrio e harmonia com a natureza, equilíbrio esse representado como constitutivo das relações ecológicas das quais estaríamos desconectados. Assim, conforme avalia Grün (id.), haveria uma verdade ambiental - anistórica e transcendental - a ser reencontrada. Indicamos, no próximo excerto, alguns elementos que associamos à constituição dessa representação cultural de natureza, valendo-nos, agora, de respostas obtidas junto às professoras que participaram do curso:

Pesquisadora - E o que te chamou atenção nesse curso de Ecoalfabetização e Ecopedagogia?

Camila - Dentro do curso, o que me chamou a atenção foi a questão, assim, do ser como um todo. Não apenas o homem separado dos outros seres. Mas o ser como um todo. Todos os seres são importantes. Estão dentro da natureza. Então, tanto os vegetais, tanto as bactérias, né... não importa. Todos os seres têm a sua trajetória de vida e a gente tem que procurar viver harmonicamente com todos. Então, de repente, a gente tem um surto de gripe, por exemplo, porque houve algum desequilíbrio dentro da natureza, dentro daquelas questões ambientais que levaram a isso. Então, se a gente procurar viver harmonicamente com todos os seres... que nós vivemos aqui no planeta... e então, dentro disso, a gente vai conseguir ter uma caminhada melhor (Entrevista realizada no dia 28/06/2004, destaques nossos).

Essa professora acentua que tal aspecto, referente à dependência mútua entre os seres vivos ("o ser como um todo"), foi uma das questões que mais a marcaram na abordagem desenvolvida durante o curso, reiterando a necessidade de mudanças na forma como nos posicionamos em relação à "natureza". Isto é, o que se propõe nessa perspectiva é que não nos situemos mais à margem da "natureza", como se vivêssemos separados dos demais seres vivos, mas que aprendamos a conviver e a habitar o mesmo planeta harmonicamente. Quantas vezes, em educação ambiental, já não ouvimos ou enunciamos 
essa afirmação que, de tanto ser repetida, quase soa como um dogma: "Nós, seres humanos, fazemos parte do meio ambiente"? Grün (2003), no texto "O conceito de holismo em ética e educação ambiental", problematiza a ampla aceitação dessa premissa pelos/as educadores/as ambientais, que resulta, no seu entender, de uma apressada e, portanto, pouco refletida substituição de um paradigma mecanicista/cartesiano por um paradigma holista. Para o autor (id.), o prestígio de que o enfoque holístico desfruta em educação ambiental deve-se, em grande parte, à forte divulgação (e, ouso dizer, quase veneração) dos trabalhos de Fritjof Capra no Brasil. Entretanto, Grün (ibid.) indica que um dos maiores problemas éticos e epistemológicos acarretados por essas posturas holísticas é que, nelas, os seres humanos estariam de tal modo "integrados" ao meio ambiente que não seria mais possível distinguir "natureza" de "cultura".

Latour, Schwartz e Charvolin (1998), por outro lado, observam que "as diferenças entre o humano e o não-humano, o cultural e o natural, o artificial e o dado, são o resultado das divisões coletivas, e não a sua causa" (p. 114). Dessa forma, tanto a propalada separação entre seres humanos e "natureza" é um produto discursivo quanto a necessidade de uma união entre essas duas categorias. Mas isso não significa que a ênfase dada a esses aspectos na educação ambiental, e em outras instâncias discursivas, não seja de extrema importância. Pelo contrário, é fundamental estudarmos, discutirmos e problematizarmos essa inversão que está sendo fomentada - deixarmos de nos considerar seres autônomos e senhores da natureza para nos transformarmos em apenas mais uma parte da natureza, submetidos à sua vontade. No entanto, em tal discussão o foco não seria o desvelamento da verdade sobre a relação entre ser humano e natureza, senão a indicação da transformação cultural que se estaria processando com mais intensidade desde a segunda metade do século passado e produzindo uma série de efeitos sociais e identitários. 


\section{Lições da natureza - alfabetização ecológica e a produção de narrativas interessadas}

A partir desse sistema de representações culturais que configura a existência de uma grave crise ecológica, apontada reiteradamente como derivada do distanciamento dos referenciais que deveriam reger a organização das sociedades humanas e que ressalta a necessidade da manutenção do indissolúvel vínculo que nos liga a todos os demais seres vivos, muitos/as poderiam fazer-se as seguintes perguntas: mas como viver de outra forma? Como alcançar (ou "recuperar", como está assinalado nas propostas que enfatizam tal questão) o equilíbrio da sociedade com a natureza? Esse é o impasse ao qual a alfabetização ecológica pretende responder. Assim, a alfabetização ecológica surge para propiciar uma "definição operacional de sustentabilidade" (CAPRA, 2003a, p. 20).

Como diz o próprio Capra (2003a), "não precisamos inventar as comunidades humanas sustentáveis a partir do zero, mas podemos moldá-las de acordo com os ecossistemas naturais, que são comunidades sustentáveis de plantas, animais e microrganismos" (p.20). Ou, como Philippe Layrargues (2003) destaca em sua crítica a essa variante da educação ambiental introduzida por Capra, a alfabetização ecológica é apresentada como a grande solução para "a aberração da natureza competitiva e conflituosa do humano, causadora da crise ambiental" (p.10).

Para lograrem reintegrar-se aos ecossistemas que lhes dão sustento e reaverem o equilíbrio perdido, as pessoas deverão, então, buscar inspiração na natureza para que seja possível modelar-se o desenvolvimento das sociedades em consonância com pressupostos retirados do funcionamento dos ecossistemas. Mas, para tanto, seria preciso aprender a ler essa natureza, seria preciso uma alfabetização ecológica. Capra (2003b) afirma que, embora as comunidades humanas diferenciem-se consideravelmente de outras comunidades de seres vivos, elas devem "seguir os princípios básicos da ecologia para lidar com o mundo material, se quiserem sobreviver por um longo tempo" (p. 2). As pessoas podem ser consideradas ecologicamente alfabetizadas 
somente após compreenderem esses "princípios da ecologia" e viverem em conformidade com eles. $\mathrm{O}$ autor (id.) destaca, ainda, que esses princípios podem ser entendidos como "leis de sustentabilidade", tão severas quanto qualquer outra lei natural.

Apresentamos, a seguir, um excerto de um texto que foi utilizado como material de apoio no curso pesquisado e que aborda algumas questões que merecem ser debatidas:

O estudo da ecologia nos traz a consciência de que a nossa felicidade depende da "felicidade" do meio e que é impossível construí-la isoladamente, [o que] nos dá imediatamente uma direção de luta, uma compreensão da interdependência que temos do todo e uma forma de entender e construir a realidade (TEXTO ANALISADO, p. 2, destaques nossos).

Latour, Schwartz e Charvolin (1998) advertem que "não há fato concernente à ecologia sem o segredo da fabricação" (p. 117). Esses autores (id.) argumentam na direção de não se tomarem os fatos científicos como estabilizados e esvaziados de sua história, de seus instrumentos, de suas disputas e de suas instituições. Nesse sentido, nos sentimos instigadas a questionar: de qual ecologia se está falando no excerto de texto apresentado acima? Sob que condições ela está sendo produzida (sobretudo discursivamente)? Em quais pressupostos baseiase essa abordagem ecológica que fundamenta a ecoalfabetização? Como a ecologia, nesse caso específico que estamos considerando, está construindo uma forma de entender a realidade? Que leituras da natureza são ensinadas nos princípios ecológicos em que se assenta a alfabetização ecológica? De que maneira essas lições de natureza buscam influenciar a organização da sociedade e, mais especificamente, as condutas das pessoas?

Evidentemente, não nos estamos dispondo a responder a perguntas tão abrangentes e complexas neste artigo, mas as compreendemos como questões relevantes, mesmo que formuladas para serem deixadas em suspenso, pois pensamos que colocá-las impede, de certa forma, que o debate sobre a alfabetização ecológica se cristalize ou em atitudes de aceitação irrestrita ou de resistência 
inflamada. Assim, argumentamos que essa ramificação da educação ambiental, que alguns autores chamam de 'biologizante' ou 'biologicista ${ }^{10}$, antes de ser apontada como "certa" ou "errada" frente a algum modelo desejado de educação ambiental, precisa ser pensada como uma importante produtora de representações culturais.

Não obstante seja duramente criticada por diversos teóricos ligados à educação ambiental, essa tendência é muito freqüentemente encontrada nas práticas desse campo, especialmente naquelas que se desenrolam no ambiente escolar. Por esse motivo, acreditamos que, ao invés de simplesmente rechaçar ou descartar a alfabetização ecológica, por estar ela supostamente na contramão das direções assumidas pela educação ambiental na atualidade, é preciso problematizá-la, tentando entender como ela se institui, que significados está produzindo e como está atuando na constituição das identidades dos educadores ambientais. Essa necessidade acentua-se ainda mais diante do "sucesso" que a proposta da alfabetização ecológica vem obtendo, e isso, certamente, não pode ser desconsiderado.

Por todos esses motivos, convém analisar os princípios ecológicos que subsidiam a ecoalfabetização, buscando atentar para como estes constroem uma determinada representação cultural de natureza que serve de modelo para uma organização idealizada da sociedade. Como já foi dito, os discursos ecoalfabetizadores representam a natureza como perfeita, harmônica e, principalmente, sábia. É precisamente devido a essa última característica que se atribui à natureza o papel de "professora", ou melhor, de alfabetizadora, já que é com ela que devemos (re)aprender a viver de forma equilibrada e ambientalmente sustentável. Tal aspecto foi abordado do seguinte modo durante o curso que analisamos:

Um caminho possível [para a sustentabilidade] é observar como a natureza resolve os problemas em cada tipo de ambiente, propôs Henrique; já que o design

10 Apesar disso, consideramos importante destacar que a abordagem dada à ecoalfabetização durante o curso pesquisado (bem como na abordagem desenvolvida por Capra) não se restringiu apenas a aspectos relacionados à Biologia, mas também a outras ciências, como a Química, a Física e a Geologia. 
ambiental [isto é, as estruturas criadas pela natureza] é o "único professor que nós temos (...), é um para cada lugar" (DIÁRIO DE CAMPO, 20/10/2003, destaques nossos).

Destacou-se, assim, no curso, na esteira das proposições formuladas por Capra (1996; 2003a), a necessidade de atentarmos para as soluções desenvolvidas pela natureza, as quais foram chamadas de "design ambiental" e que variariam de acordo com o lugar que estivéssemos considerando. A afirmação de que o design ambiental é o único professor que nós temos associa-se fortemente a algumas representações culturais que consideram que a cultura é (ou, ao menos, deveria ser) um reflexo das características do meio ambiente. Nessa direção, a cultura deve, portanto, adequar-se ao design ambiental de cada local. Entretanto, lançando um olhar orientado pela perspectiva dos estudos culturais, procuramos pensar nessas estratégias referidas como utilizadas pela natureza, nesse "design natural", bem como nos princípios ecológicos selecionados por Capra (2003a) e expostos no curso, como narrativas interessadas sobre a natureza, que são produzidas culturalmente. Interessadas porque, nelas, a natureza assume significados específicos em conformidade com os objetivos específicos das ações de ecoalfabetização.

Assim, se por um lado a natureza representada culturalmente no discurso publicitário (AMARAL, 1997b) constrói determinados significados, que se referem a valores e conceitos que auxiliam a vender mais produtos, a natureza que encontramos nos discursos da ecoalfabetização está implicada na produção de ensinamentos voltados à preservação da natureza, configurada como frágil e ameaçada. Cabe destacar, no entanto, que, em nenhuma das duas situações, se está falando da natureza "em si", de uma natureza não mediada pela cultura, mas sim de construções discursivas específicas que visam cumprir certas finalidades. Como afirma Isabel Carvalho (2004), "não se trata de postular sua interpretação [da natureza] como decodificação de uma ordem natural subjacente a todo acontecimento" (p. 168). Ocorre justamente o contrário, pois 
a interação com o ambiente ganha caráter de inter-relação, na qual aquele se oferece como contexto do qual fazemos parte, envolvidos que somos pelas condições ambientais, ao mesmo tempo em que nós, como seres simbólicos e portadores de linguagem, produzimos nossa visão e nossos recortes, construindo percepções, leituras e interpretações do ambiente que nos cerca. Assim, inscrevemos as condições naturais em que vivemos em nosso mundo de significados, transformando a natureza em cultura (CARVALHO, op.cit., p.165 e 166, destaque nosso).

Porém, é necessário salientar que as representações culturais relacionadas à ecoalfabetização, diferentemente, por exemplo, das narrativas publicitárias, são sustentadas por explicações científicas, provenientes principalmente da Biologia. Desse modo, tais narrativas da Biologia estão atravessando a educação ambiental não "por acaso" e disso decorre a importância de atentarmos para os efeitos que estão sendo por elas produzidos. Isso pode ser verificado na alfabetização ecológica que, ao se valer de conceitos ecológicos para influenciar condutas sociais (e morais), apela para atributos que definem o caráter das verdades científicas: a sua isenção e incontestabilidade. $\mathrm{Na}$ construção de uma ecoalfabetização com base em conceitos científicos, acionam-se, portanto, representações culturais de ciência bastante naturalizadas na sociedade. Entre outros aspectos que poderíamos mencionar, destacamos que tais representações definem a ciência como o principal meio de desvelar o funcionamento dos processos naturais, tomando-a como um trabalho neutro e isento de subjetividades, como um modo privilegiado de explicar o mundo e, enfim, como contendo explicações capazes de sobreporem-se a quaisquer outras explicações.

Apesar disso, existem algumas correntes teóricas, como os estudos culturais de ciência ${ }^{11}$, que buscam distanciar-se da tendência que trata a ciência como um conjunto de conhecimentos capazes de serem desconectados das instâncias contingentes em que foram produzidos e às quais eles se referem (WORTMANN; VEIGA-NETO, 2001). Desse modo, os estudos culturais propiciam que se entendam as

11 (9) Ver, por exemplo, o livro "Estudos culturais de ciência \& educação", de Maria Lúcia Wortmann e Alfredo Veiga-Neto (2001). 
categorias que aprendemos como próprias ou inerentes à Biologia como construções/invenções operadas na cultura (SANTOS, 2000). Contudo, "a biologia não está sozinha na produção do mundo, mas suas narrativas dão substrato a outras narrativas que, se não partem dela, utilizam-se de e se reforçam com seus elementos" (id., p. 243). Nesse caso, vemos, por exemplo, a educação ambiental e, mais especificamente, a alfabetização ecológica fagocitando determinados conceitos e utilizando-os para fins que não foram projetados quando essas narrativas biológicas foram produzidas.

Vamos discutir brevemente como foram apresentados no curso que acompanhamos (e cujo tema, vale lembrar, era ecopedagogia e ecoalfabetização) os "princípios ecológicos" selecionados por Capra (2003a) para subsidiarem a alfabetização ecológica e, conseqüentemente, para servirem como modelo para a construção de uma sociedade humana sustentável. Capra (ibid.) afirma que "os princípios da ecologia são os princípios de organização comuns a todos esses sistemas vivos. São os padrões básicos da vida" (p. 22). Esses princípios são descritos da seguinte forma: "nenhum ecossistema produz resíduos, já que os resíduos de uma espécie são o alimento de outra; a matéria circula continuamente pela teia da vida; a energia que sustenta estes ciclos ecológicos vem do Sol; a diversidade assegura a resiliência; a vida, desde o seu início há mais de três bilhões de anos, não conquistou o planeta pela força, e sim através de cooperação, parcerias e trabalho em rede" (ibid., p. 25).

Não é nosso objetivo problematizar extensamente todos os conceitos trabalhados no curso; pretendemos apenas trazer algumas questões que nos ajudem a pensar como a abordagem desenvolvida pela ecoalfabetização está atuando na instituição de educadores ambientais e, assim, construindo uma determinada forma de fazer educação ambiental. Nesse sentido, apresentamos dois trechos do diário de campo que tratam da "cooperação" / "parceria" como uma característica inerente à "natureza":

Abordou-se no curso o conceito de parceria, destacando que, da teoria da evolução, o que é mais ressaltado é a competição, assemelhando-se à organizaçãa 
de nossa sociedade capitalista, onde "quem vence é o mais forte". O professor ressaltou que essa é "uma mentira", "uma leitura bumana errada", já que "força não tem nada a ver com aptidão" (DIÁRIO DE CAMPO, 08/10/2003, destaques nossos).

O professor explicou que "o que manda é a cooperação", que faz com que "todos se acomodem sem precisar competir" e que isso é "exatamente o contrário do que aprendemos". Usou como exemplo os 'carnívoros', dizendo que eles "não competem entre si apesar de utilizarem os mesmos recursos, pois trabalham em horários diferentes". (...) Assim, ele prosseguiu, "a natureza consegue se multiplicar em formas de vida e se sobrepor, sem 'stress". O professor disse, também, que, quando um animal come outro, está ocorrendo uma relação de cooperação, ele come os mais fracos, os doentes e faz com que a espécie melhore. (...) Também foi afirmado que outra má interpretação consiste em imaginar que há violência na naturez̧a, pois "quando um animal mata o outro, não há violência nenhuma, ele está alimentando-se” (DIÁRIO DE CAMPO, 08/10/2003, destaques nossos).

Esses excertos exibem alguns aspectos interessantes quanto à leitura da natureza proposta pela alfabetização ecológica. É bem enfatizada a necessidade de se proceder a uma nova interpretação das relações ecológicas: a competição, bastante enfatizada na teoria da seleção natural, passa a ser suplantada pela cooperação, já que se pretende mostrar que na natureza não há lugar para conflito, pois as relações devem ser vistas como harmoniosas. Assim, a leitura "humana" que se fazia ao se buscarem elementos na natureza que justificassem a competitividade e a "seleção natural" da sociedade capitalista, remetendo às abordagens do "darwinismo social", é apontada como equivocada pelos discursos da ecoalfabetização. Como destaca Layrargues (2003), agora, com a crise ambiental, as analogias entre sociedade e natureza seguem ocorrendo, mas com o sinal invertido, "fornecendo justificativas para a harmonização dos seres humanos entre si e com a natureza" (p. 12). 


\section{Mais alguns desdobramentos...}

Como já mencionamos, Philippe Layrargues (2003) empreendeu uma crítica bastante contundente à alfabetização ecológica, a qual rendeu acaloradas respostas em espaços de discussão - principalmente os virtuais -, provenientes do próprio Capra (2003b), bem como de outros autores brasileiros que partiram em defesa das propostas desse prestigiado autor. Iremos resgatar alguns pontos dessa crítica formulada por Layrargues (2003) que contribuem para problematizar algumas representações culturais praticadas durante o curso acompanhado. Esse autor (id.) identifica na ecoalfabetização um acentuado determinismo ecológico, na medida em que essa se vale da transposição de regras da natureza para governar a sociedade. De acordo com essa perspectiva, as comunidades humanas seriam regidas pelos já mencionados princípios ecológicos que se estão buscando inculcar por meio das práticas de educação ambiental. Como vimos nos trechos do diário de campo apresentados acima, as relações naturais são qualificadas como cooperativas, mesmo quando se trata de relações que podem ser consideradas negativas, como a predação. Dessa forma, pretende-se estimular a sociedade a espelhar-se nas características (morais) da natureza - no caso, a cooperação - para conduzir as relações entre os seres humanos.

Além disso, Layrargues (ibid.) ressalta que na ecoalfabetização efetua-se uma dogmatização da dimensão virtuosa da natureza, visto que se superdimensionam as características consideradas positivas em detrimento das que podem ser vistas como negativas. Assim, "a lista de princípios destacados por Capra $(1996 ; 1999)$ retrata uma natureza paradisíaca, onde impera o reino da harmonia, do equilíbrio interno, da cooperação, da parceria" (2003, p. 8). Layrargues (ibid.), inclusive, cita algumas características da natureza que, a partir de um ponto de vista moral, nada têm de valorosas, podendo ser consideradas defeituosas. $\mathrm{O}$ mesmo autor (ibid.) argumenta, então, que a seleção dos princípios ecológicos que fundamentam a alfabetização ecológica obedece a critérios ideológicos explícitos e não a um suposto padrão universal que regeria as comunidades de seres vivos, como propõe Capra (2003a). 
Frente a essas operações que estão sendo, até aqui, discutidas, parece-nos que não é a sociedade que está sendo biologizada, mas a natureza que está sendo humanizada, já que as características que estão sendo atribuídas à natureza na alfabetização ecológica são categorias eminentemente culturais. Veiga-Neto (1994) indica, por exemplo, que em muitas práticas relacionadas à educação ambiental "os animais são humanizados, em suas feições e sentimentos". Julgar que a natureza seja virtuosa, harmoniosa, equilibrada é tanto uma construção cultural e situada em um tempo determinado quanto considerá-la competitiva, defeituosa ou imoral. É, portanto, bastante apropriada para esse contexto a afirmação feita por Santos (2000) de que "o próprio conhecimento biológico - que se diz descrever a natureza mesma das coisas - está 'recheado' de significados que circulam na cultura popular" (p. 243).

É possível dizer, então, que as classificações, nomeações e definições que são tomadas de empréstimo da Biologia pela alfabetização ecológica fazem mais do que uma simples descrição do mundo natural, elas produzem os seres e suas relações de formas específicas. A partir das perspectivas teóricas que nos orientam, a linguagem não está sendo entendida como um meio de mimetizar a realidade tal "como ela é", mas está comprometida com a própria construção do que compreendemos ser a realidade. Isso, obviamente, pode ser estendido para a ciência... Então, a Biologia, ao falar dos seres vivos, não está referindo-se a entidades pré-existentes, mas está construindo e naturalizando as formas com que representamos e nos relacionamos com esse mundo vivo. Como ressalva Santos (id.), quando fazemos essas considerações, não estamos negando a existência de uma materialidade física dos seres vivos, sua existência prévia no mundo, anterior à nomeação. O que pretendemos explicitar é que fatos naturais também são fenômenos discursivos (ibid.). Dessa maneira, o "natural" é novamente apresentado como justificativa daquilo que uma sociedade aprova ou deseja, ainda que seja a cultura que, de qualquer modo, determine esse "natural", como assinala Williamson (apud AMARAL, 2000a).

A alfabetização ecológica atua como mais uma das formas de "fabricar" culturalmente o que se entende por "natural" e por 
"natureza" e, assim, fomenta comportamentos e modos de vida compreendidos como mais adequados. Por esses aspectos, consideramos extremamente necessário que os "discursos ecoalfabetizadores" (bem como outros discursos relacionados ao campo da educação ambiental) continuem sendo problematizados e discutidos.

\section{Referências bibliográficas}

AMARAL, Marise B. Representações de naturęa e a educação pela mídia. Dissertação (Mestrado) Programa de Pós-Graduação em Educação / UFRGS, Porto Alegre, 1997a.

O que a natureza vende? Um olhar sobre as representações de natureza no discurso publicitário. Educação \& realidade, Porto Alegre, v.22, n.2, p.117-132, jul/dez, $1997 b$.

- Natureza e representação na pedagogia da publicidade. In: COSTA, Marisa V. (org.). Estudos culturais em educaşão: mídia, arquitetura, brinquedo, biologia, literatura, cinema... Porto Alegre: Ed. Universidade/UFRGS, 2000.

CALVINO, Ítalo. Palomar. São Paulo: Companhia das Letras, 1994.

CAPRA, Fritjof. A teia da vida: uma nova compreensão científica dos sistemas vivos. São Paulo: Cultrix, 1996.

Alfabetização ecológica: o desafio para a educação do século 21. In: TRIGUEIRO, André (org.). Meio ambiente no século 21. Rio de Janeiro: Sextante, 2003 a.

O ponto de mutação já passou: entrevista com Fritjof Capra. Entrevista concedida à EcoAgência de Notícias. Disponível em: http://univali.br/rebea/entrevista _capra.htm. Acesso em: 22 out. 2003b. 
CARVALHO, Isabel Cristina M. Educação, natureza e cultura: ou sobre o destino das latas. In: ZAKRZEVSKI, Sônia B.; BARCELOS, Valdo (org.). Educação ambiental e compromisso social: pensamentos e ações. Erechim: EdiFAPES, 2004.

GRÜN, Mauro. Ética e educação ambiental: a conexão necessária. Campinas: Papirus, 1996.

O conceito de holismo em ética e educação ambiental. In: ENCONTRO DE PESQUISA EM EDUCAÇÃO AMBIENTAL - EPEA, 2, São Carlos. Anais... São Carlos: UFSCar, 2003. CD-ROM.

GUIMARÃES, Leandro B.; SAMPAIO, Shaula M.V. Praticando estudos culturais em articulação com a educação ambiental. In: ZAKRZEVSKI, Sônia B.; BARCELOS, Valdo (org.). Educação ambiental e compromisso social: pensamentos e ações. Erechim: EdiFAPES, 2004. p.125-146.

HALL, Stuart. Representation, cultural representations and signifying practices. London: Thousands Oaks; New Delhi: Sage, 1997.

KESSELRING, Thomas. O conceito de Natureza na História do pensamento ocidental. Episteme, Porto Alegre, n.11, p.153-172, jul/dez, 2000.

LATOUR, Bruno; SCHWARTZ, Cécile; CHARVOLIN, Florian. Crises dos meios ambientes: desafios às ciências humanas. In: ARAÚJO, Hermetes R. (org.). Tecnociência e cultura: ensaios sobre o tempo presente. São Paulo: Estação Liberdade, 1998.

LAYRARGUES, Philippe P. Determinismo biológico: o desafio da Alfabetização Ecológica na concepção de Fritjof Capra. In: ENCONTRO DE PESQUISA EM EDUCAÇÃO AMBIENTAL - EPEA, 2., São Carlos. Anais... São Carlos: UFSCAR, 2003. CD-ROM.

SAMPAIO, Shaula M.V. Notas sobre a "fabricação" de educadores/ as ambientais: identidades sob rasuras e costuras. Dissertação (Mestrado em Educação). - Programa de Pós Graduação em Educação / UFRGS, Porto Alegre, 2005. 
SANTOS, Luís Henrique S. A Biologia tem uma história que não é natural. In: COSTA, Marisa V. (org.). Estudos culturais em educação: mídia, arquitetura, brinquedo, biologia, literatura, cinema... Porto Alegre: Ed. Universidade/UFRGS, 2000.

VEIGA-NETO, Alfredo. Ciência, ética e educação ambiental em um cenário pósmoderno. Educação \& realidade, Porto Alegre, v.19, n.2, p.141-169, jul/dez, 1994.

WORTMANN, Maria Lúcia C. Investigação e educação ambiental: uma abordagem centrada nos processos de construção cultural da natureza. Educação: teoria e prática, Rio Claro, v. 9, n. 16 e 17, p. 36-42, jan/jun e jul/dez, 2001a.

- Da inexistência de um discurso unitário para falar da natureza. In: SCHMIDT, Sarai. A educação em tempos de globalização. Rio de Janeiro: DP\&A, 2001b.

WORTMANN, Maria Lúcia C.; VEIGA-NETO, Alfredo. Estudos culturais da ciência e educação. Belo Horizonte: Autêntica, 2001. 